\title{
Representational Systems in Zoosemiotics and Anthroposemiotics Part II: On Meta- Representation and Human Language
}

\author{
Vilém Uhlír \\ Theoretical and Evolutionary Biology, Department of Philosophy and History of Sciences. Charles University. Viničná 7, 12843 Praha 2, Czech Republic
}

Received ???, 2018; Accepted ???, 2018

\begin{abstract}
Following the conclusions of the previous paper (Uhlir, this issue), this paper adopts a theory that is based on the notion that the essence of language is uniquely human, with no homologue elsewhere in nature, and advances the possibility that human language is discontinuous not only within communication systems but also within representational systems. Linguistic data from disparate sources in Homo sapiens are contrasted with evidence from animals. After briefly discussing the dialectics between the mosaic approach to language and the holistic approach to an integrated left hemisphere, the paper culminates in a proposal of a general zoosemiotic theory of "Representational Systems" and a special anthroposemiotic theory of "Meta-representational Systems".

Keywords: language $\bullet$ syntax $\bullet$ representation $\bullet$ meta-representation $\bullet$ zoosemiotics $\bullet$ anthroposemiotics $\bullet$ talking animals $\bullet$ general cognition - representational systems $\bullet$ evolutionary discontinuity $\bullet$ biosemiotics

(c) Sciendo
\end{abstract}

\section{The Problem of Language}

Generally, we can say that linguists do not agree on what properties of language are the core ones. This topic is often opaque and not easily approachable for scientists outside linguistics. The concept of language is at least dual (for a summary of this paradigmatic divide in linguistics, see Ref. [1]): One conception of language sees it as a semantic system (for instance, the Distributed Language Group linguists or Cognitive linguists: these groups lay emphasis on the enactedness/embodiedness of language - this approach is represented by linguists such as Lakoff, McCawley and Halliday), whereas the other group sees language as a syntactic system (proponents of generative grammar - for instance, Chomsky, Pinker and Lightfoot). Linguists adhering to the generative grammar school of linguistics often explicitly acknowledge and highlight differences in linguistic capabilities between human and non-human entities. Proponents of other linguistic approaches disagree, often vehemently. This distinction between syntax and semantics can be seen as one theoretical "axis" of approach to language, and this axis concerns "what language is"; the second "axis" concerns "what language does": is it for communication or for representation, mental language, thinking and so on. We can categorise particular linguistic theories along these two axes.

Natural human language, in the nativist stance, is a discrete combinatorial system of hierarchically recursive syntax [2-9]. A highly structured syntactical system plays a fundamental, even profound, role at all levels of language - grammar, morphology and semantics. These components of language constitute different levels of syntactic patterning - it seems that recursive syntax recursively permeates language [10-14] to the extent that language is sometimes described as having a syntactic core [2-5, 8, 9, 15-17]. Other parts of language (phonology, for instance) seem to lack true recursion and use hierarchical discrete infinity instead (Uhlir, this issue). This suggests that language might have a mosaical structure.

It is clear that language (or at least some of its aspects) must be unique to humans, because no other stance can explain the fact that chimpanzees, our closest living relatives, reared identically to human children, cannot acquire linguistic competence (despite their impressive feats in other cognitive domains). ${ }^{1}$ This raises interesting questions

1 See the "sceptic" bulk of literature on the so-called "Talking Animal" projects [6, 18-35].

\footnotetext{
*Corresponding author: Vilém Uhlir, E-mail: uhlir.vilem@gmail.com 
about the evolution of language, especially when we think of it as a complex mosaic.

It seems, at least viewed from the nativist stance, that human language is an inborn, species-specific, neural specialisation - a specialised cognitive module, which, during human evolution, recruited domain-specific organic structures and distinct modules of cognitive processing, both with specific functions, into a tightly (inter)connected whole, resulting in complex mutual structuration of the left hemisphere [6, 7, 36-39]. This resulted in the view that the left hemisphere as a whole is a "language organ" [37]. This nativist claim is strongly supported by numerous lines of evidence from (at least two, for the sake of brevity) disparate sources: 1) from the process of language acquisition by small children [9, 40-44]; and 2) from neurological localisation of linguistic faculties within the left hemisphere [6, $7,45-48]$. This evidence warrants the addressing of the dialectic between language being a complex mosaic and the evidence suggesting that it is a compact whole.

The nativist evolutionary account of language, espoused by scientists inspired by Chomsky's vision of biolinguistics, ${ }^{2}$ as codified by Berwick and Chomsky [53], is that a random mutation resulted in an evolutionary event during which the domain-specific cognitive structures were recruited into a tightly connected whole, resulting in the complex mutual structuration of the left hemisphere, with syntax permeating the interwoven whole. This seems to suggest that syntax, i.e. the "merge", is the unifying principle. ${ }^{3}$ This resulted in something akin to a "language of thought" (purely internal to the mind). This cognitive novelty immediately brought increased fitness to the individuals possessing it, and it quickly spread through the breeding group of early Homo sapiens. Once this evolutionary trait had spread through a sufficient part of the population, a different selective pressure caused the trait to be eventually externalised (via interfacing with sensory-motor and conceptual-intentional systems [56-58], possibly by another random mutation, into phonetic communication - the spoken language. Berwick and Chomsky [53 p. 37] suggested that this happened approximately between 200,000 and 60,000 years ago, which is surprisingly backed by Enard et al. [59], who calculated the chronology of the selective sweep that fixed the FOXP2 ${ }^{4}$ allele in the human population roughly 200,000 years ago. This, in turn, resulted in even tighter interweaving across human cognition (see Ref. [64] for a comprehensive overview of evolution of language, and see Ref. [65] for the biolinguistic perspective; papers in both largely present the image above).

Things are further complicated by the fact that in today's humans, language has not a single adaptive function (in the sense of language often being described as being "for communication"), which often results in language being treated as a monolithic whole. ${ }^{5}$ When researching an evolutionary trait, the current function might be confused with the original function it was selected for. Various authors $[55-58,68]$ subjected the language faculty to fractionation and decomposition into component mechanisms, which can be studied on various levels of scientific inquiry. They have advanced a hypothesis that only recursion is special to human language (the "Recursion-only hypothesis") and is the feature that distinguishes human language from other forms of animal communication. Fitch and Hauser adopted this decompositive approach in order to be able to use comparative stances and techniques, suggesting that at least some of the apparently novel aspects of human language (those non-recursive ones) will be revealed as being based on mechanisms widely shared among various species. However, we cannot reliably determine the chronological order in which the different aspects of (human) language emerged (especially in the absence of palaeontological evidence of language, as stated by Chomsky [5]), although we can glean some evidence from the comparative techniques. Language, described from this stance as a complex mosaic, is a vast set of complex mechanisms, shaped by adaptation and selected for a great variety of adaptive reasons. Each of the mechanisms comprising language possibly has its own separate function, phylogeny and evolutionary history. Language, i.e. its syntactic core, might, quite plausibly, have precursors outside of communication, as Fitch and Hauser noted.

It is evident that there are two different approaches that are relevant for this paper - the nativist stance $[37,66$, 67] seeing language as a complex, unified, adaptation for communication. Proponents of this approach argue for a holistic approach to language and argue that human language as a whole is a qualitative evolutionary discontinuity. The second is the mosaical approach used by Fitch and Hauser [55-58, 68], wherein language is fractioned into sets of sub-skills for easier inter-species evolutionary comparison. Mosaical approach focusses on evolutionary

2 Bound to Chomsky's minimalist programme [49-52].

3 Chomsky refers to a basic syntactic operation that he calls the "Merge", recursive in nature, which results in generative grammar mechanisms $[50-52,54]$. What Chomsky means by "Merge" is what Hauser and Fitch [55] recognize as "Recursion".

4 FoxP2 (the mouse version shared among mammals) is a gene widely shared among vertebrates, and its FOXP2 version is involved in human oro-motor control [60-62]. For the sake of brevity, it is not the "gene for language" as the popular press has nicknamed it. The human gene differs in terms of two substituted amino acids from the gene of other primates [59]. DNA sampling of bones from Homo neanderthalensis indicates that its FOXP2 gene is a little different from the $H$. sapiens variant [63].

5 See Refs. $[55,58]$ for detailed discussion of this decomposition-into-parts approach; see Refs. [66, 67] for refutation of this approach. 
continuities and largely ignores the discontinuities. This paper presents an intermediary - or "third" - approach, aspiring to reconcile both semantic with syntactic approaches to language and the nativist stance with the mosaical approach. It should be noted that I am not actually advocating such solution yet but merely suggesting that it may be seriously entertained.

\section{Comparison of Human Language and Animal Communication Systems}

\subsection{Animal Communication (in Nature)}

Animal calls are usually mediated by the limbic system of the brain; they are bound to the inner state of the animal, and calls are bound to the immediate presence of the stimulus, except as a mistake [34, 69-72]. Lower primates do not utter signals in the absence of their referent or the emotional state they reflect (this, however, happens in play contexts) and do not easily learn to control their vocalisations. The response of vervet monkeys to an alarm call, although different for each type of danger, is invariant and probably limbically controlled [73, 74]. Compositional semanticity in the communication of monkeys or apes seems to be extremely rare ${ }^{6}$ as their signals - for the most part - reflect inner affections $[73,74,76,77]$. Non-human signals are acoustically continuous and are processed in a continuous manner [78, 79]. Monkey and ape calls show only one level of syntactic patterning (linear concatenation) and involve unproductive compounding of units. Animal calls are mostly inborn and later fine-tuned by maturation and experience and evoke a stereotypical response. Animal communication is holistic and processed in a continuous manner [80-82].

\subsection{Human Language}

By contrast, human language clearly involves brain parts outside the limbic region (neocortex [83]) and linguistic behaviour is consciously controlled (for the neuroanatomy of language and for the language in the left hemisphere [45-47, 84-90]). Words are typically produced without limbic involvement and are not necessarily bound to the inner state; words are not bound to the stimulus and (usually) do not evoke a stereotypical behavioural response in the hearer (although this can be gained by conditioning to particular words). Language is referential and words are, in a certain sense, uncoupled from their referents. Language signals are processed as functionally discrete (though their relation to one another is acoustically continuous - see emic vs. etic dilemma in Ref. [91]) and processed as functionally discrete units. Language signals are not holistic but "sliced" into units. Discrete processing of human language allows semantically productive compounding of units in all levels of syntactic patterning (grammar and morphology). Particular languages are taught, yet the language capacity is inborn [6-9, 37, 92-94].

\subsection{Comparison of Small Children and Trained Animals}

The "Talking Animal" projects (described in Uhlir, this issue) often resorted to the inter-species comparison of linguistic productions of the trained animals with the utterances of very young children, as well as the comparison of cognitive capacities of trained animals with those of young children. Both comparisons are, however, tricky and seem to have backfired on the researchers. Let us consider the differences in linguistic productions of small children and the utterances of trained animals:

First, as opposed to trained animals, who are claimed to consistently use symbol position in concatenations, the productions of even very young children contain syntactic expression of the semantic roles. ${ }^{7}$ Although their early use in children might be ungrammatical in a particular language, it is still syntactic [95-98]. This means a consistent use of syntactical mechanisms for expressing semantic roles. All natural languages have grammatical means for indicating the semantic roles of the nominal elements in sentences, but we cannot find this in any of the utterances of the "talking animals" (see Uhlir, this issue, chapter on syntax) [7, 20-22, 26, 27, 30-32, 34, 99-103]. On the other hand, we cannot know for sure whether or not the animals learned to think (represent) in semantic roles. If

6 In Cercopithecus diana and C. campbelli, the combinations of signals mean something different than standalone signals [75], although their communication system does not show any hints of hierarchy or recursion.

7 Thematic roles (or semantic roles) is a term used to express the role that a noun phrase plays in relation to the governing verb (usually, the main verb in a sentence). For example, thematic roles are agent-patient, instrument, force and cause. Thematic roles express the semantic relations that the entities denoted by the noun phrases have towards the main verb. The syntactic arguments are subjected to syntactic variation in terms of syntactic functions, whereas the thematic roles of the arguments (of the given predicate) remain consistent, even as the form of that predicate changes. 
this would be the case, the animals were unable to syntactically express it, as Premack [25] suspected. Children do show signs of differentiated dealing with certain words, according to their roles, which constrain their use in concatenation due to long-distance dependencies [104, 105]; evidence hails also from children's mistakes [106]; for constraints in early utterances, see Ref. [107]. Trained animals do not show this differentiated approach to words according to their semantic roles.

Second, there is a total absence of predicate-argument structure in the utterances of trained animals: this is the most common argument against the claims of linguistic capacities of trained animals $[7,20-22,26,27,30-32,34$, 99-103]. For voluminous evidence of argument structure in young children, see Refs. [105, 108-113].

Third, the sequences taught to, and produced by, language-trained animals were ambiguous and did not include phrase markers (as noted by Kako [115]). ${ }^{8}$ This means that the animals might have solved the sentences in a nonsyntactic manner using only linear stringing (as suggested, evidenced and sourced by numerous researchers [26, $27,30-32,34,103]$. For the evidence on phrase markers and function words in children in general, see Refs. [116, 117 p. 55, 118]; this robust conclusion is also backed by evidence of children pausing in patterns [119] and is evident from the written language of deaf children [120]. Although neuroanatomical differences between adults and children exist in this context [121], children, unlike trained animals, are able to use phrase markers reliably.

Fourth, in the case of "True Recursion and Center Embedding" (see Uhlir, this issue, chapter on "Recursion"), in no animal subject has it been unambiguously shown that it understands that the elements are "bound" from inside out (or outside inwards) in such a way that the elements at the beginning and at the end of the string are associated and related, that the following next-to-first and next-to-last are associated and so on, as in a sentence in natural human language. For evidence in children, see Refs. [122-124] for constraints.

Fifth is the argument of the Poverty of the Stimulus [4]. This argument attempts to explain how children develop a capacity to distinguish possible and impossible syntactical structures in a particular language through ordinary experience, without being explicitly taught to distinguish these. The linguistic stimuli that a young child is exposed to are not entirely adequate to explain the process of learning a particular language, as the knowledge seems to be supplemented with some sort of innate linguistic capacity that provides additional knowledge. On the other hand, the innate natural language grammar is underdetermined, so it must be supplemented by experience of a particular language. Poverty of the Stimulus describes the dialectics of innate grammar and a particular grammar of a language that a child is exposed to [125-135].

Some of the researchers who trained great apes claim that by certain measures of intelligence (standard intelligence quotient [IQ] and Piagetian scales of cognitive development), chimpanzees and gorillas are the equals of young children (up until 2-3 years of age), and it is not until after the early stages of language development (after 3 years of age) that children leave the apes behind [23, 136-138]. Purely on (abstract) measures of cognitive functions, then, the apes (who cannot use syntax) seem to be comparable with children (who do use syntax). Yet, cognitively handicapped children have been shown to use syntax in their utterances [43, 139-143]; the evidence also suggests that standard syntax is present even in microcephalic children [144 p. 21, 145 p. 186, 146-148]. Therefore, syntactic deficits cannot logically be ascribed to the lack of intelligence - although, of course, the language capacity must be supplemented by other cognitive domains for the normal language to arise (see Ref. [149] for evidence of argument structure deficiency in Down syndrome children). In the case of the trained animals, it seems they are quite competent in some or all of the other cognitive domains [24, 25, 150-155], but they lack the recursive syntactic capacity (Uhlir, this issue) [7, 20-22, 26, 27, 30-32, 34, 99-103]. This comparison strongly supports the nativist claim.

\subsection{Semantics and Syntax Have Different Neurocognitive Substrates in Humans}

It is known that (in humans) semantic meaning and syntactic grammar have (at least partially) separate neural substrates and differ significantly in lateralisation and even temporal processing.

Syntactic information seems to be processed in the left frontotemporal network (in a certain part of Broca's area), whereas more general communicative abilities - semantics of a sentence - seem to be processed bilaterally in the frontotemporal system, although mostly in the lower portion of the left inferior gyrus [156, 157]. Ullman [158] has shown that mental lexicon and mental syntax have different neurocognitive substrates - mental lexicon depends on declarative memory (in the temporal lobe), while syntactic meta-information is based in the frontal

8 Phrase markers are used mostly in generative theories of syntactic structure [114]; phrase markers are constituents of specific syntactic categories represented in trees of phrase markers, and nodes in the trees are labelled according to the category they belong to. 
cortex and basal ganglia (left inferior frontal areas). This is further supported by Miozzo et al. [159], who have found that morphological inflection deficits (in their case study, a plural suffix) related to aphasic brain lesions occur independently of semantic and phonological impairments, as the aphasia patient they studied had problems with inflection use rather than with lacking the concept numerosity or phonological deficit.

Recursive syntactic skills are more lateralised than semantic functions [160-163]. Damage to semantic abilities may be compensated by normal or elevated activity in the right hemisphere; damage to the left frontotemporal network, however, causes both syntactic and morphological deficits (both in comprehension and production), for which the right hemisphere cannot compensate [157]. Moreover, syntactic performance correlates with tissue integrity in the left frontotemporal network; however, semantic performance correlates with activity in the right superior/middle temporal gyri regardless of tissue integrity [157].

Syntactic violations and nonsense sentences elicit different temporal processings [164]. The neurocognitive evidence, gleaned from a variety of disparate cross-modal distraction tasks that differentiated syntactic and semantic aspects of sentence comprehension, seems to be suggesting that the human brain reacts to syntax violations even when these violations are not consciously detected. The brain produces a characteristic early neural response pattern, which is distinct from the pattern invoked in conscious detection of syntactic violations [165-167]. This indicates that even such a highly complex computational process, which syntactic processing surely is, can be processed outside conscious awareness.

\section{Conclusions and Discussions}

Following the presented evidence, I agree with Fitch and Hauser that language as a whole ("broad language faculty" in Fitch and Hauser's terminology) is indeed an "adaptation" for communication with conspecifics (other humans). It is still an interconnected whole that does not have a single "function in contemporary" humans. Hierarchically recursive syntax ("narrow language faculty" in their terminology) is not an adaptation for communication per se (or, rather, might not have originally been one). However, current neurocognitive research mentioned herein does not seem to support the mosaical domain-specific approach to "human" language, as recursive syntax seems to be permeating the whole left hemisphere in "contemporary" humans - it has even been expanding its externalisation into other cognitive domains, aiming to interface with them [168]. Despite knowing that homologues to recursion might be found in domains different from those for communication (Uhlir, this issue), we have as yet no unambiguous hint of evolutionary chronology of language - whether the recursivity was developed first and later was recruited for communication, and then syntax integrated the left hemisphere into a compact interwoven whole under different selective pressures; or whether recursive syntax first appeared parallel to proto-language and after co-opting other cognitive domains, it was externalised into spoken language, which only then "bound" the domains into an integrated left hemisphere. The chronology of the recruitment of distinct cognitive domains, as well as their subsequent merging under syntax into an interwoven network complex in the left hemisphere, remains unclear. It seems that at some time point in human evolution, recursive syntax has been a unifying agent.

We have seen that syntax operates on an unconscious, automatic, autonomous and reflex-like basis [166], although it is accessible to reflexive consciousness. In Uhlir (this issue), we have also seen that claims of the presence of syntax in non-human species warrant caution. On the surface, it "may" have looked like the animals have simulated conversation, but in fact they acquired neither human language nor something similar to one: what they have learned was not non-instrumental, there was no "language for language's sake" - what the animals had rather acquired was a system of habits or conditioned behaviours [20-22, 26, 27, 30-32, 34, 99-103, 169]. This seems to indicate that an animal, no matter how intelligent, in the wild or in captivity, cannot acquire human language as a compact whole, as an interconnected system (Broad Language, Hauser and Fitch) (see Uhlir, this issue; compare this conclusion with those in Refs. [4, 6, 30-32, 34, 35, 49]). If animals would be capable of acquiring language as a whole, surely at least chimpanzees would have had acquired it by now.

The trained animals certainly did achieve something. The fundamental questions are the following: What was it? And how did they achieve it?

The facts seem to be unambiguously supporting the inaccessibility of syntax to non-human minds. The solution I have suggested, and it should be noted that I am not actually advocating such a solution yet but merely suggesting that it may be seriously entertained, differs substantially from the mosaic solution that Hauser and Fitch put forward in their papers. 
Hauser and Fitch suggest that the pseudo-linguistic feats of trained animals could very well be due to either homologies of the relevant organic neural structures found in humans or convergent evolution of analogous domainspecific systems. I suggest that the partial approximations to linguistic feats in trained animals are due to their capability to simulate them using mostly general cognition. In other words, I suggest that animals used alternative strategies to achieve their "pseudo-linguistic feats". This itself is a claim that does not contribute anything novel, although, when stated explicitly, it might be useful as a stepping stone for further consideration of how this ties to the problem of language in general.

Language as a systematic whole is (usually) primarily situated within the left hemisphere, whereas general cognition is spread within both hemispheres; moreover, it has been shown that general cognition is correlated with global grey matter [170]. Although recent research attention is mostly focussed on identifying domain-specific taxonomic differences in cognition (the so-called "grain approach" [171]), domain-general differences also exist [172]. Moreover, evolutionary logic does not necessarily dictate that the innate mind has to consist, mostly or even exclusively, of domain-specific features [171]. An important paper by Deaner et al. [172] has proven, using complex Bayesian analysis, that some taxa consistently outperform others across a range of disparate cognitive tests. Certain taxa differ significantly in overall performance. These results cannot be explained by perceptual biases or any other contextual confounders and, instead, suggest that primate taxa differ from others in some kind of domain-general ability. This seems to be the case for general cognition [170, 171, 173 chs. 5 and 8]), arising as an emergent phenomenon from the "grain" of specific domains (for sophisticated discussions, see papers by Roberts [174]). For a review of older literature concerning phenomenological descriptions of what it feels like to use the right hemisphere (general cognition) and the left hemisphere (syntax-influenced cognition) [175].

An animal with sufficient semantic abilities, general intelligence and cognitive capacity, "might" be able, after very intensive training, to virtually, in its mind, simulate certain components of language (which, in turn, justifies the use of mosaical domain-specific approach to language, suggested by Fitch and Hauser, in "non-humans"), which are otherwise bound to "human" neural specialisation. In the study by Fitch and Hauser [56], we have seen that non-humans are stuck trying to interpret strings generated at higher level of sophistication (phrase-structure grammar), with equipment being able to process only strings generated by a lower level of sophistication (finite state grammar). I propose that a virtual architecture, within general cognition, would crudely and imperfectly simulate the performance of a neurological language specialisation. Animals could parse strings incorporating recursive syntax only via semantic processing (which, in turn, brings back to question the reasonable approach to language - whether it should be approached as a syntactic or semantic system). We also know that semantic processing is bound to general cognition [176]. By analogy, cats, dogs, goats and bears are not disposed to walk bipedally, the same way as humans are, yet they can learn to walk bipedally for short distances. Even though they are able to walk bipedally, they do not walk in the same manner as humans, their gait is physiologically different - and that is simply an anatomical fact. Surface similarity does not mean the deep mechanisms and principles used to achieve this similarity are the same, and it does not necessarily imply a deep homology [68]. Considering the available evidence, I suggest that especially in the case of great apes trained in language, these animals did not need domain-specific homologies to the relevant neural structures for their achievements but could achieve their "pseudo-linguistic feats" by using crude simulation of syntactic parsing via semantic processing relying on general cognition. Once again, it should be noted that I am not actually advocating such a solution yet but am merely suggesting that it may be seriously entertained.

There is one possibility to turn this claim into a testable theory. The key to this is the Wada Test [177-180], as it was used as a definitive proof of left hemisphere dominance in linguistic faculty. In the Wada Test, the left hemisphere is temporarily anaesthetised, while the right hemisphere remains fully conscious (and has full control over the hand on the other side of the body). If we place an object in the hand (of the "human" subject) that is controlled by the anaesthetised hemisphere, the patient will not be able to name the object after the anaesthetic wears off. However, if we show the object to the eye corresponding to the anaesthetised hemisphere, the patient will not be able to name the object but will be perfectly capable of drawing it. What happens during the Wada Test? The input of what the patient felt in his/her hand, or saw with one eye, did not register in his/her consciousness, because the left hemisphere (with its recursively syntactic linguistic capacity) was temporarily turned off. We can, however, see that the information about the object was registered but not consciously (and linguistically). Exactly the same results can be seen in "split brain" patients [181-187] or in patients with aphasia [96, 188-191].

The experiments outlined do not only simply illustrate that the storage of lexical items is located (usually) in the left hemisphere; they also tell us the important thing about how experience, at least in humans, is represented 
and processed by two distinct modules or pathways, which are integrated in conscious activity. One module (probably semantic) processes direct sensory information (and is possibly not completely accessible to reflective consciousness) and represents this information in mental concepts (and stores it in memory). The other module (probably syntactic) somehow either processes the direct sensory information in parallel, or accesses the alreadyrepresented version, and represents the information again in the medium of language (or rather, in recursively syntactic (meta)representation, which includes the "propositional structure and predicate-argument structure"). This (re)representation is accessible to reflexive consciousness.

If we were allowed to use the Wada Test on some of the remaining "talking" animals (preferably a chimp), it should be possible to prove whether or not the animal is using general cognition to simulate language components or specialised centres homologous to those found in humans (in case chimps have a pre-adaptation for language). Because of taxonomical proximity with chimpanzees, we could temporarily turn off the chimp homologies of the relevant human neural structures and judge whether the non-human subject uses general cognition for semantic processing in order to achieve its "pseudo-linguistic feats".

From what can be gleaned from the evidence obtained from the Wada Test, namely about the (hypothetical) parallel processing of sensory information by two modules, I believe the problem of language can be re-framed in a novel way. In humans, the semantic module processes direct sensory information into representations, and the other syntactic module somehow either processes the direct sensory information in parallel - or accesses the alreadyrepresented version - and represents the information again in recursively syntactic re-representation, which uses the "propositional structure and predicate-argument structure". It seems that the formal syntactic representational system interacts with both sensory-motor and conceptual-intentional systems (Fitch and Hauser). Syntax is yielding re-structurations of representations (for lack of better description) at these interfaces. This recursive metamapping, unique to humans, recruited, sometime during evolution, other domains and integrated interfaces with them (or outright co-opted them) during the Recursive Merge. I suggest we should call this recursive meta-mapping "the Meta-representation".

Meta-representation might be an interface between syntactic and semantic: syntactic system parallelly maps the same inputs (which are, at the same time, mapped semantically) into recursively syntactic form, yet at the same time interfacing with the purely semantic representations. Some of the evidence seems to be suggesting that human cognition is parasitic on the syntactic structure of language. This is a position adopted by a minority of writers (in the generative tradition, [192-196]) but otherwise remains highly contentious. This is, however, not exactly what this paper suggests - I am suggesting that language (Broad Language, Fitch and Hauser) is an externalised manifestation of this Meta-representation System selected for communication. Terrace [197] has shown that language evolutionarily presupposes metacognition (such phenomena as Theory of Mind, shared gaze and joint attention), which suggests that language, as a communication tool, evolved in ancestors who had already been selected for their ability to meta-represent. The question is whether such phenomena might have been precursors to certain domain-specific skills later co-opted by Recursive Merge, or whether they were allowed by recursive syntax interfacing with their domains. We can extend this question into asking whether Theory of Mind, for instance, is based on syntactic embedding (a string within a string) or allows it - as the Theory of Mind, seen as multi-order intentionality, is an example of recursion par excellence. Primates might share domains that allow partial meta-representation; however, recursive meta-representation had not integrated their brains into interconnected wholes as in $H$. sapiens, and certainly their meta-representation had not externalised into a communication system (language).

A meta-representational system, as suggested in this paper, operates in parallel to the representational system and interfaces with it; syntax operates on a meta-level to semantics. Representational system(s) "slice(s)" or divide(s) the perceptions into parts, into discrete units, to which corresponding signs are assigned. Representational systems are semiotic. The evidence from the "Talking Animal" projects suggests that this layer of representation is readily adopted by animals (via training and, possibly, in the wild). The additional representational system at the disposal of humans, the "Meta-representational System", either organises the already "sliced" representations according to syntactic principles, or it "slices" them in parallel to "Representational System" processing. It "slices" perceptions or representations into relatively complex, interrelated and structured concepts or proposals (for the lack of a more precise term) in which we can discern a clear pattern - the "propositional structure" ("When and where did who what to whom"). This pattern implies the differentiation of entities, their accidents, as well as their actions and states, exactly as reflected in the subject-predicate-argument structure of human natural language. The differentiation allows a differentiated approach to each class of representation. 
Representational systems can represent anything accessible to the senses - the pattern proceeds from object to perception to representation. Meta-representational systems proceed from representation to mental concept (from representation to word) and allow us to proceed from mental concept to representation (from word to representation) (see chapter on recursion and syntax in Uhlir, this issue). This allows us to construct something with no backing by sensorial data, which allows us to negotiate the models of reality. This implies a certain level of constructivism as the mode of existence that a meta-representational system imposes upon us. A view of the world of other species (most probably) contains only perceptions of it, our view contains opinions about it, and possible futures, as our modelling of reality shows plasticity and pliability. This means there might be contradictions in the models of reality, which is something most likely no other species suffers from. This development might also be responsible for the self-reflexive consciousness. It does not mean that non-human entities do not have semiosis or "umwelten" - it simply means that non-human entities lack this parallel meta-representation and, in turn, the capacity for the contradictions of reality models.

It is difficult for us to imagine how an animal sees the world without recursive syntax. Our recursively syntactic meta-representative view of reality seems natural and understandably logical to us. It does not automatically follow that this "slicing and structuring" of representations is natural and logical for other species. It is quite possible that other animals do "slice and structure" representations in a fundamentally different way that would seem illogical or syntactically monolithical to us. Animals most likely perceive something, which would seem like undifferentiated masses or monoliths of perceptions and which are not separated into individual parts following the same logic or the same principles as in humans. After all, animal signalling and communication (and probably perception as well) are holistic and syntactically unstructured (though certainly semantically structured [198]) - the perceptual monoliths of animals might be circular in nature, unlike syntactic representation in humans, which seems to be based on linear statements.

There is a fundamental problem with inter-species communication - for us, the meaning is carried mainly via syntax. Animals cannot acquire syntax of the human type; therefore, it is difficult for us to discern how animals engage in semiosis, and scientists have to produce ingenious experiments to find this out. The meanings of the asyntactic utterances of the animals trained in the "Talking Animal" projects remain ambiguous for us - the question is, whether the animals have communicated anything meaningful for us at all.

There is no way out of this anthropomorphism - it is our mental equipment that represents things syntactically in our meta-representational system. It is our nature. We have no way of judging the pseudo-linguistic utterances of the research subjects in the "Talking Animal" projects, or at least no other way than analysing them semantically. The "talking animals" are in a position analogous to a human diver walking clumsily on the sea floor - the diver does not have gills, he/she is not equipped to live underwater and his/her body cannot filter oxygen from the sea. The diver ("aquanaut") can, however, use different methods to stay under water for short periods of time. No matter how big the oxygen bomb is - the bomb will not make him/her a marine animal. Analogically, no "talking animal" can do more than simulate human language via general cognition (or use homologues of the relevant neurological specialisations), no non-human "logonaut" can acquire human species-specific adaptation - the metarepresentational system, of which language is a manifestation.

This approach seems to be reconciling both semantic and syntactic approaches to language, as language, seen as an externalisation of the meta-representational system into the communicative interface, is both semantic and syntactic. Furthermore, this approach seems to vindicate the assumption that we can distinguish language from its usage - what language "is" from what it "does" (which, also, might be seen as the key assumption of biosemiotics in general [199 ch. 5]). I have tried to show that one can retain the ontological stance of linguistic nativism and yet can still appreciate the competence of animals, although not recursively syntactic or linguistic, clearly seen in their "pseudo-linguistic feats". Moreover, the fallacious argument (espoused by cognitive linguists or adherents of the distributed language theory) that adopting the nativist stance leads to inevitable conclusions, as searching for language abilities outside humans is "unproductive" in this paradigm, has been proven wrong.

\section{Acknowledgements}

I would like to thank Anton Markoš for reviewing the thesis that this text is based on and for providing advice, suggestions and guidance. This paper is dedicated to my ex-colleague, collaborator and teacher, Marco Stella. This paper is a shortened version of my master's thesis, with inclusions of parts from my unpublished popular book, named "Logonauts", on the same topic. 
[1] Harris, R.A., 1995. The linguistics wars. Oxford: Oxford University Press.

[2] Chomsky, N., 1965. Aspects of the theory of syntax. Cambridge, MA: MIT Press.

[3] Chomsky, N., 1968. Language and mind. New York: Harcourt, Brace and World.

[4] Chomsky, N., 1980. Rules and representations. New York, NY: Columbia University Press.

[5] Chomsky, N., 1986. Knowledge of language: Its nature, origin and use. New York: Praeger.

[6] Pinker, S., 1984. Language learnability and language development. Cambridge, MA: Harvard University Press.

[7] Pinker, S., 1995. The language instinct: How the mind creates language. New York, NY: Harper Perennial.

[8] Berwick, R.C., 1985. The acquisition of syntactic knowledge. Cambridge, MA: MIT Press.

[9] Lightfoot, D., 1982. The language lottery: Toward a biology of grammars. Cambridge, MA: MIT Press.

[10] van der Hulst, H., 2010. Re recursion. In van der Hulst, H. (Ed.), Recursion and human language. Germany: Mouton de Gruyter

[11] van der Hulst, H., 2010. A note on recursion in phonology. In van der Hulst, H. (Ed.), Recursion and human language. Germany: Mouton de Gruyter, pp. 285-300.

[12] van der Hulst, H. (Ed.) 2010. Recursion and human language. Germany: Mouton de Gruyter.

[13] Karlsson, F., 2010. Recursion and iteration. In van der Hulst, H. (Ed.), Recursion and human language. Germany: Mouton de Gruyter, pp. 4368.

[14] Perfors, A., Tenenbaum, J., Gibson, E., et al., 2010. How recursive is language? A Bayesian exploration. In van der Hulst, H. (Ed.), 2010. Recursion and human language. Germany: Mouton de Gruyter, pp. $159-178$.

[15] Jackendoff, R., 1972. Semantic interpretation in generative grammar. Cambridge, MA: MIT Press.

[16] Jackendoff, R., 1977. X-bar syntax: A study of phrase structure. Cambridge, MA: MIT Press.

[17] Bever, T.G., 1970. The cognitive basis for linguistic structures. In Hayes, J.R. (Ed.), Cognition and the development of language. New York: Wiley and Sons, pp. 279-362.

[18] Sebeok, T.A., Rosenthal, R. (Eds.) 1981. The Clever Hans phenomenon: Communication with horses, whales, apes, and people. Annals of the New York Academy of Sciences, Vol. 364.

[19] Umiker-Sebeok, J., Sebeok, T.A. (Eds.) 1980.
Speaking of apes: A critical anthology of two-way communication with man. Berlin: Springer.

[20] Terrace, H., Petitto, L.A., Sanders, R.J., et al., 1979. Can an ape create a sentence? Science, 206 4421, 891-902.

[21] Terrace, H., Petitto, L.A., Sanders, R.J., et al., 1980. On the grammatical capacity of apes. In Nelson, K. (Ed.), Children's language, vol. 2. New York: Gardner Press, pp. 371-495.

[22] Terrace, H., Petitto, L.A., Sanders, R.J., et al., 1981. Ape language. Science, 211, 87-88.

[23] Premack, D., 1983. The codes of man and beasts. Behavioral and Brain Sciences, 6(1), 125-37.

[24] Premack, D., 1984. Possible general effects of language training on the Chimpanzee. Human Development, 27, 268-281.

[25] Premack, D., 1988. Minds with and without language. In Weiskrantz, L. (Ed.), Thought without language. A Fyssen Foundation Symposium. New York: Calderon Press, 46-65.

[26] Seidenberg, M.S., Petitto, L.A., 1979. Signing behavior in apes: A critical review. Cognition, 7, 177-215.

[27] Seidenberg, M.S., Petitto, L.A., 1981. Ape signing: Problems of method and interpretation. In Sebeok, T.A., Rosenthal, R. (Eds.), The Clever Hans phenomenon: Communication with horses, whales, apes, and people. Annals of the New York Academy of Sciences, Vol. 364, pp. 94-114.

[28] Sebeok, T.A., 1980. Looking in the destination for what should have been sought in the source. In Umiker-Sebeok, J., Sebeok, T.A. (Eds.), Speaking of apes: A critical anthology of two-way communication with man. Berlin: Springer, pp. 407-428.

[29] Sebeok, T.A., 1981. The ultimate enigma of "Clever Hans": The union of nature and culture. In Sebeok, T.A., Rosenthal, R. (Eds.), The Clever Hans phenomenon: Communication with horses, whales, apes, and people. Annals of the New York Academy of Sciences, Vol. 364, pp. 199-205.

[30] Wallman, J., 1992. Aping language. Cambridge, UK: Cambridge University Press.

[31] Anderson, S.R., 2004. Doctor Dolittle's delusion: Animals and the uniqueness of human language. New Haven, CT: Yale University Press.

[32] Tomasello, M.E., 1994. Can an ape understand a sentence? A review of language comprehension in ape and child by E. D. Savage-Rumbaugh et al. Language and Communication, 14, 377-390.

[33] Tomasello, M.E., 1999. The cultural origins of 
human cognition. Cambridge, MA: Harvard University Press.

[34] Tomasello, M.E., 2007. If They're so good at grammar, Then why don't they talk? Hind from apes' and humans' use of gestures. Language, Learning and Development, 3, 133-156.

[35] Pinker, S., 1994. How could a child use verb syntax to learn verb semantics? Lingua, 92, 377-410.

[36] Passingham, R.E., 1979. Specialization and the language areas. In Steklis, H., Raleigh, M.J. (Eds.), Neurobiology of social communication in primates. New York: Academic Press, pp. 221-256.

[37] Anderson, S.R., Lightfoot, D.W., 2002. The language organ: Linguistics as cognitive physiology. Cambridge, UK: Cambridge University Press.

[38] Gleitman, L.R., Gleitman, H., Landau, B., et al., 1988. Where learning begins: Initial representations for langage learning. In Newmeyer, F.J. (Ed.), Linguistics: The Cambridge Survey vol. III. Language: Psychological and biological aspects. New York: Cambridge University Press, pp. 150193.

[39] Gleitman, L.R., 1986. Biological dispositions to learn language. In Demopoulos, W., Madras, A. (Eds.), Language leasing and koncept acquisition: Foundational issues. Norwood, NJ: Ablex, pp. 3-28.

[40] Bowerman, M., 1973. Early syntactic development. Cambridge, UK: Cambridge University Press.

[41] Clark, H.H., Clark, E.V., 1977. Psychology and language. New York: Hartcourt Brace.

[42] Cromer, R., 1981. Reconceptualizing language acquisition and cognitive development. In Scheifelbusch, R.L., Bricker, D.D. (Eds.), 1981. Early language: Acquisition and intervention. Baltimore: University Park Press, pp. 53-102.

[43] de Villiers, J.G., de Villiers, P.A., 1978. Early language. Cambridge, MA: Harvard University Press.

[44] Newport, E.L., Gletiman, H., Gleitman, L.R., 1977. Mother, i'd rather do it myself: Some effects and non-effects of maternal speech style. In Snow, C.E., Ferguson, C.A. (Eds.), Talking to children: Language input and acquisition. Cambridge, UK: Cambridge University Press, pp. 109-149.

[45] Josse, G., Mazoyer, B., Crivello, F., et al., 2003. Left planum temporale: An anatomical marker of left hemispheric specialization for language comprehension. Cognitive Brain Research, 18(1), $1-14$.

[46] Josse, G., Hervé, P., Crivello, F., et al., 2006. Hemispheric specialization for language: Brain volume matters. Brain Research, 1068(1), 184193.

[47] Josse, G., Tzourio-Mazoyer, N., 2004. Hemispheric specialization for language. Brain Research Reviews, 44(1), 1-12.

[48] Witelson, S.F., 1977. Anatomic asymmetry in the temporal lobes: Its documentation, phylogenesis and relationship to functional asymmetry. In Diamond, S.J., Blizard, D.A. (Eds.), Evolution and lateralization of the brain. Annals of The New York Academy of Sciences, Vol. 299, pp. 328-354.

[49] Chomsky, N., 1995. The minimalist program. Cambridge, MA: The MIT Press.

[50] Boeckx, C., 2006. Linguistic minimalism: Origins, concepts, methods and aims. Oxford: Oxford University Press.

[51] Boeckx, C. (Ed.) 2006. Minimalist essays. Amsterdam: John Benjamins.

[52] Al-Mutairi, F.R., 2014. The minimalist program: The nature and plausibility of Chomsky's biolinguistics. Cambridge, UK: Cambridge University Press.

[53] Berwick, R.C., Chomsky, N., 2016. Why only us: Language and evolution. Cambridge, MA: MIT Press.

[54] Chomsky, N., 1999. Derivation by phase. Cambridge, MA: The MIT Press.

[55] Hauser, M., Chomsky, N., Fitch, T., 2002. The faculty of language: What is it, who has it, and how did it evolve? Science, 2985598, 1569-1579.

[56] Fitch, T., Hauser, M., 2004. Computational constraints on syntactic processing in a Nonhuman primate. Science, 303(56), 377-380.

[57] Hauser, M., Fitch, T., 2003. What are the uniquely human components of the language faculty? In Christiansen, M., Kirby, S. (Eds.), Language evolution. Oxford: Oxford University Press, pp. 158-181.

[58] Fitch, T., Hauser, M., Chomsky, N., 2005. The evolution of the language faculty: Clarifications and implications. Cognition, 97(2), 179-210.

[59] Enard, W., Przeworski, M., Fisher, S.E., et al., 2002. Molecular evolution of FOXP2, a gene involved in speech and language. Nature, 4186900, 869-872.

[60] Vargha-Khadem, F., Watkins, K., Alcock, K., et al., 1995. Praxic and nonverbal cognitive deficits in a large family with a genetically transmitted speech and language disorder. Proceedings of the National Academy of Sciences, 92(3), 930-933.

[61] Vargha-Khadem, F., Gadian, D.G., Copp, A., et al., 2005. FOXP2 and the neuroanatomy of speech and language. Nature Reviews Neuroscience, 6(2), 131-138.

[62] MacDermot, K.D., Bonora, E., Sykes, N., et al., 
2005. Identification of FOXP2 truncation as a novel cause of developmental speech and language deficits. The American Journal of Human Genetics, 76(6), 1074-1080.

[63] Krause, J., Alueza-Fox, C., Orlando, L., et al., 2007. The derived FOXP2 variant of modern humans was shared with Neandertals. Current Biology, 17(21), 1908-1912.

[64] Christiansen, M., Kirby, S. (Eds.) 2003. Language evolution. Oxford: Oxford University Press.

[65] Di Sciullo, A.M., Boeckx, C. (Eds.) 2011. The biolinguistic enterprise: New perspectives on the evolution and nature of the human language faculty. Oxford: Oxford University Press.

[66] Pinker, S., Jackendoff, R., 2005. The faculty of language: what's special about it? Cognition, 95(2), 201-236.

[67] Jackendoff, R., Pinker, S., 2005. The nature of the language faculty and its implications for evolution of language (Reply to Fitch, Hauser, and Chomsky). Cognition, 97(2), 211-225.

[68] Fitch, T., 2011. "Deep homology" in the biology and evolution of language. In Di Sciullo, A.M., Boeckx, C. (Eds.), The biolinguistic enterprise: New perspectives on the evolution and nature of the human language faculty. Oxford: Oxford University Press, pp. 135-168.

[69] Sebeok, T.A. (Ed.) 1977. How animals communicate. Bloomington, Indiana: Indiana University Press.

[70] Witzany, G. (Ed.) 2014. Biocommunication of animals. Netherlands: Springer.

[71] Maynard-Smith, J.,; Harper, D., 2003. Animal signals. Oxford: Oxford University Press.

[72] Marler, P., 1984. Animal communication: Affect or cognition? In Scherer, K.R., Ekman, P. (Eds.), Approaches to emotion. Hillsdale: Lawrence Erlbaum Associates, pp. 345-65.

[73] Seyfarth, R.M., Cheney, D.L., 1982. How Monkeys see the world: Areview of recent research on East African Vervet Monkeys. In Snowdon, C.T., Brown, C.H., Petersen, M.R. (Eds.), Primate communication. Cambridge, UK: Cambridge University Press, pp. 239-52.

[74] Seyfarth, R.M., Cheney, D.L., 1986. Vocal development in vervet Monkeys. Animal Behaviour, 34, 1640-58.

[75] Zuberbühler, K., 2002. A syntactic rule in forest monkey communication. Animal Behaviour, 63(2), 293-299.

[76] Marler, P., 1977. The evolution of communication. In Sebeok, T.A. (Ed.), How animals communicate. Bloomington, IN: Indiana University Press, pp. 45-
70.

[77] Demers, R.A., 1988. Linguistics and animal communication. In Newmeyer, F.J. (Ed.), Linguistics: The cambridge survey vol. III. Language: Psychological and biological aspects. New York: Cambridge University Press, pp. 314335.

[78] Rendall, D., Owren, M.J., 2013. Communication without meaning or information: Abandoning language-based and informational constructs in animal communication theory. In Stegmann, U.E. (Ed.), Animal communication theory: Information and influence. Cambridge, UK: Cambridge University Press, pp. 151-188.

[79] Haven Wiley, R., 2013. Communication as a transfer of information: Measurement, mechanism and meaning. In Stegmann, U.E. (Ed.), Animal communication theory: Information and influence. Cambridge , UK: Cambridge University Press. pp. 113-132.

[80] Bowling, D.L., Fitch, W.T., 2015. Do animal communication systems have phonemes? Trends in Cognitive Sciences. DOI: 10.1016/j. tics.2015.08.011

[81] Yip, M.J., 2006. The search for phonology in other species. Trends in Cognitive Sciences, 10(10), 442-446.

[82] Marler, P., 2000. Origins of music and speech: Insights from animals. In Wallin, N., Merker, B., Brown, S. (Eds.) The origins of music. Cambridge: The MIT Press, pp. 31-48.

[83] Barton, R.A., Dunbar, R., 1997. Evolution of the social brain. In Byrne, R., Whiten, A. (Eds.), Machiavellian intelligence II. Cambridge, UK: Cambridge University Press, pp. 240-263.

[84] Petrides, M., 2013. Neuroanatomy of language regions of the human brain. Elsevier: Academic Press.

[85] Ardila, A., Ostrosky-Solis, F. (Eds.) 1989. Brain organization of language and cognitive processes. New York, NY: Plenum Publishing Company.

[86] Breznitz, Z. (Ed.) 2007. Brain research in language. Berlin: Springer.

[87] Schnelle, H., 2010. Language in the brain. Cambridge, UK: Cambridge University Press.

[88] Lamb, S.M., 1999. Pathways of the brain: The neurocognitive basis of language. Amsterdam: John Benjamins Publishing Company.

[89] Pulvermüller, F., 2002. The neuroscience of language: On brain circuits of words and serial order. Cambridge, UK: Cambridge University Press.

[90]Wray, A.J., 1992. The focusing hypothesis: The 
theory of left hemisphere lateralised language re-examined. Amsterdam: John Benjamins Publishing Company.

[91]Pike, K.L., 1967. Language in relation to a unified theory of structure of human behavior. The Hague, Netherlands: Mouton.

[92]Bloom, P., 2000. How children learn the meanings of words. Cambridge, MA: MIT Press.

[93] Taylor, C., 2016. The language animal: The full shape of the human linguistic capacity. Cambridge, MA: Harvard University Press.

[94]Lieberman, P., 2013. The unpredictable species: What makes humans unique. Princeton, $\mathrm{NJ}$ : Princeton University Press.

[95] Jackendoff, R., 1987. The status of thematic roles in linguistic theory. Linguistic Inquiry, 18, 369-411.

[96]Saffran, E.M., Schwartz, M.F., Linebarger, M.C., 1998. Semantic influences on thematic role assignment: Evidence from normals and aphasics. Brain and Language, 62(2), 255-297.

[97]Bornkessel, I., Schlesewsky, M., Comrie, B., et al., (Eds.) 2006. Semantic role universals and argument linking: Theoretical, typological, and psycholinguistic perspectives. Berlin: de Gruyter Mouton.

[98]Luraghi, S., Narrog, H. (Eds.) 2014. Perspectives on semantic roles. Amsterdam: John Benjamins Publishing Company.

[99]Terrace, H.S., 1979. Nim: A Chimapnzee who learned sign language. New York: Knopf.

[100] Terrace, H.S., 1979. How Nim Chimpsky changed my mind. Psychology Today, November 1979, pp. 65-76

[101] Terrace, H.S., 1980. More on Monkey talk: Response to Patterson 's rejoinder to Martin Gardners review of Nim and speaking of apes. New York Review of Books, 4 December 1980, p. 59.

[102] Terrace, H.S., 1981. A report to the academy, 1980. In Sebeok, T.A., Rosenthal, R. (Eds.), The Clever Hans phenomenon: Communication with horses, whales, apes, and people. Annals of the New York Academy of Sciences, Vol. 364, pp. 94-114.

[103] Terrace., 1984

[104] Bowerman, M., 1990. Mapping thematic roles onto syntactic functions: Are children helped by innate linking rules? Linguistics, 28(6), 12531289.

[105] Noble, C.H., Rowland, C.F., Pine, J.M., 2011. Comprehension of argument structure and semantic roles: Evidence from english-learning children and the forced-choice pointing paradigm.
Cognitive Science, 35(5), 963-982.

[106] Deffler, S.A., Fox, C., Ogle, C.M., et al., 2016. All my children: The roles of semantic category and phonetic similarity in the misnaming of familiar individuals. Memory \& Cognition, 44(7), 989-99.

[107] Brooks, P., Tomasello, M., 1999. How children constrain their argument structure constructions. Language, 75(4), 720-738.

[108] Theakston, A.L., 2012. "The spotty cow tickled the pig with a curly tail": How do sentence position, preferred argument structure, and referential complexity affect children's and adults' choice of referring expression? Applied Psycholinguistics (04), 691-724.

[109] McClure, K., Pine, J.M., Lieven, E.V.M., 2006. Investigating the abstractness of children's early knowledge of argument structure. Journal of Child Language, 33(04), 693-720.

[110] Peter, M., Chang, F., Pine, J.M., et al., 2015. When and how do children develop knowledge of verb argument structure? Evidence from verb bias effects in a structural priming task. Journal of Memory and Language, 81, 1-15.

[111] Naigles, L.R., Lehrer, N., 2002. Languagegeneral and language-specific influences on children's acquisition of argument structure: A comparison of French and English. Journal of Child Language, 29(03), 545-566.

[112] Braine, M.D.S., Brody, R.E., Fisch, S.M., et al., 1990. Can children use a verb without exposure to its argument structure? Journal of Child Language, 17(02), 313-342.

[113] Naigles, L.R., Maltempo, A., 2011. Verb argument structure acquisition in young children: Defining a role for discourse. Journal of Child Language, 38(03), 662-674.

[114] Chomsky, N., 1957. Syntactic structures, Second Edition 2002. Berlin: Mouton de Gruyter.

[115] Kako, E., 1999. Elements of syntax in the systems of three language-trained animals. Learning \& Behavior, 27(1), 1-14.

[116] Powers, S., 2001. A minimalist approach to phrase structure acquisition. In Alexandrova, G.M., Arnaudova, O. (Eds.), The minimalist parameter: Selected papers from the open linguistics forum, Ottawa, 21-23 March 1997, pp. 33-50.

[117] Fodor, J.D., Crain, S., 1987. Simplicity and generality of rules in language acquisition. In MacWhinney, B. (Ed.), Mechanisms of language acquisition: Proceedings of the 20th Annual Carnegie Mellon Symposium on Cognition. Hillsdale, NJ: Lawrence Erlbaum Associates, pp. 
$35-64$.

[118] Friederici, A.D., 1983. Children's sensitivity to function words during sentence comprehension. Linguistics, 21(5), 717-739.

[119] Maloney, E.M., Payne, D.L., Redford, M.A., 2012. What children's pause patterns indicate about their constituent structure. In BUCLD 36 Proceedings Supplement. Boston, MA.

[120] Taeschner, T., Devescovi, A., Volterra, V., 1988. Affixes and function words in the written language of deaf children. Applied Psycholinguistics, 9(04), 385-401.

[121] Schlaggar, B.L., 2002. Functional neuroanatomical differences between adults and school-age children in the processing of single words. Science, 2965572, 1476-1479.

[122] Gass, S., Ard, J., 1980. L2 data: Their relevance for language universals. Teachers of English to Speakers of Other Languages Quarterly, 14(4), 443-452.

[123] Gaer, E.P., 1969. Children's understanding and production of sentences. Journal of Verbal Learning and Verbal Behavior, 8(2), 289-294.

[124] Karlsson, F., 2007. Constraints on multiple centerembedding of clauses. Journal of Linguistics, 43(2), 365-392.

[125] Clark, A., Lappin, S., 2011. Linguistic nativism and the poverty of the stimulus. Wiley-Blackwell.

[126] Laurence, S., Margolis, E., 2001. The poverty of the stimulus argument. The British Journal for the Philosophy of Science, 52(2), 217-276.

[127] Berwick, R.C., Okanoya, K., Beckers, G.J.L., et al., 2011. Songs to syntax: The linguistics of birdsong. Trends in Cognitive Sciences, 15(3), 113-121.

[128] Berwick, R.C., Pietroski, P., Yankama, B., et al., 2011. Poverty of the stimulus revisited. Cognitive Science, 35(7), 1207-1242.

[129] Vallauri, E.L., 2004. The relation between mind and language: The innateness hypothesis and the poverty of the stimulus. The Linguistic Review, 21(3), 345-387.

[130] Lidz, J., Waxman, S., 2004. Reaffirming the poverty of the stimulus argument: A reply to the replies. Cognition, 93(2), 157-165.

[131] Legate, J.A., Yang, C.D., 2002. Empirical reassessment of stimulus poverty arguments. The Linguistic Review, 18(1-2), 151-162.

[132] Fodor, J.D., Crowther, C., 2002. Understanding stimulus poverty arguments. The Linguistic Review, 18(1-2), 106-145.

[133] Thomas, M., 2002. Development of the concept of "the poverty of the stimulus". The Linguistic
Review, 18(1-2), 51-71.

[134] Pullum, G.K., Scholz, B.C., 2002. Empirical assessment of stimulus poverty arguments. The Linguistic Review, 18(1-2), 9-50.

[135] Lasnik, H., Uriagereka, J., 2002. On the poverty of the challenge. The Linguistic Review, 18(1-2), 147-150.

[136] Limber, J., 1977. Language in child and chimp? American Psychologist, 32, 280-95.

[137] Redshaw, M., 1978. Cognitive development in humans and gorilla infants. Journal of Human Evolution, 7, 133-141.

[138] Greenfield, P.M., Savage-Rumbaugh, S.E., 1993. Comparing communicative competence in child and chimp: The pragmatics of repetition. Journal of Child Language, 20, 1-26.

[139] Dalby, M.A., 1977. Aetiological studies in language retarded children. Neuropediatrics, 8(1), 499-500.

[140] Prior, M.R., Frolley, M., Sanson, A., 1983. Language lateralization in specific reading retarded children and backward readers. Cortex, 19(2), 149-163.

[141] Fowler, A.E., 1984. Language Acquisition of Down's Syndrome Children: Production and Comprehension. Unpublished Doctoral Dissertation, University of Pennsylvania.

[142] Paul, R., Dykens, E., Leckman, J.F., et al., 1987. A comparison of language characteristics of mentally retarded adults with fragile $X$ syndrome and those with nonspecific mental retardation and autism. Journal of Autism and Developmental Disorders, 17(4), 457-468.

[143] Abbeduto, L., Boudreau, D., 2004. Theoretical influences on research on language development and intervention in individuals with mental retardation. Development Disabilities Research Reviews, 10(3), 184-192.

[144] Fedor, A., Ittzés, P., Szathmáry, E., 2009. The biological background of syntax evolution. In Bickerton, D., Szathmáry, E. (Eds.), Biological foundations and origin of syntax. Cambridge, MA: MIT Press, pp. 15-40.

[145] Bishop, D.V.M., 2009. What can developmental language impairment tell us about the genetic bases of syntax? In Bickerton, D., Szathmáry, E. (Eds.), Biological foundations and origin of syntax. Cambridge, MA: MIT Press, pp. 185-206.

[146] Dediu, D., Ladd, D., 2007. Linguistic tone is related to the population frequency ofthe adaptive haplogroups of two brain size genes, Microcephalin and ASPM. Proceedings of the National Academy of Sciences, 104(26), pp. 
10944-10949.

[147] Woods, C.G., Bond, J., Enard, W., 2005. Autosomal recessive primary microcephaly (MCPH): A review of clinical, molecular, and evolutionary findings. The American Journal of Human Genetics, 76(5), 717-728.

[148] Lenneberg, E.H., 1967. Biological foundation of language. New York: John Wiley.

[149] Grela, B.G., 2003. Do children with Down syndrome have difficulty with argument structure? Journal of Communication Disorders, 36(4), 263-279.

[150] Pepperberg, I., 1983. Cogniton in the African Grey Parrot: Preliminary evidence for auditory/ vocal comprehension of the class concept. Animal Learning and Behavior, 11, 175-85.

[151] Pepperberg, I., 1987. Acquisition of the same/ different concept by an African Grey Parrot (Psittacus erithacus): Learning with respect to categories of color, shape, and material. Animal Learning and Behavior, 15, 423-432.

[152] Pepperberg, I., 1987. Evidence for conceptual quantitative abilities in the African Grey Parrot: Labeling of cardinal sets. Ethology, 75, 37-61.

[153] Pepperberg, I., 1990. Conceptual abilities of some nonprimate species, with an emphasis on an African Grey Parrot. In: Parker, S.T., Gibson, K.R. (Eds.), „Language" and intelligence in monkeys and apes. Cambridge, UK: Cambridge University Press, pp. 469-507.

[154] Pepperberg, I., 1990. Cognition in an African Gray Parrot (Psittacus erithacus): Further evidence for comprehension of categories and labels. Journal of Comparative Psychology, 104(1), pp. 41-52.

[155] Shettleworth, S.J., 2010. Cognition, evolution and behavior. Oxford: Oxford University Press.

[156] Dapretto, M., Bookheimer, S.Y., 1999. Form and content: Dissociating syntax and semantics in sentence comprehension. Neuron, 24(2), 427432.

[157] Wright, P., Stamatakis, E.A., Tyler, L.K., 2012. Differentiating hemispheric contributions to syntax and semantics in patients with lefthemisphere lesions. Journal of Neuroscience, 32(24), 8149-8157.

[158] Ullman, M.T., 2001. A neurocognitive perspective on language: The declarative/procedural model. Nature Reviews Neuroscience, 2(10), 717-726.

[159] Miozzo, M., Fischer-Baum, S., Postman, J.A., 2010. A selective deficit for inflection production. Neuropsychologia, 48(9), 2427-2436.

[160] Połczyńska, M., Curtiss, S., Walshaw, P., et al., 2014. Grammar tests increase the ability to lateralize language function in the Wada test. Epilepsy Research, 108(10), 1864-1873.

[161] Bornkessel, I., Zysset, S., Friederici, A.D.F., et al., 2005. Who did what to whom? The neural basis of argument hierarchies during language comprehension. Neurolmage, 26(1), pp. 221233.

[162] Menenti, L., Gierhan, S.M.E., Segaert, K., et al., 2011. Shared language: Overlap and segregation of the neuronal infrastructure for speaking and listening revealed by functional MRI. Psychological Science, 22(9), 1173-1182.

[163] Dronkers, N.F., Wilkins, D.P., Van Valin R.D.Jr., et al., 2004. Lesion analysis of the brain areas involved in language comprehension. Cognition, 92(1-2), 145-177.

[164] Yamada, Y., Neville, H.J., 2007. An ERP study of syntactic processing in English and nonsense sentences. Brain Research, 1130, 167-180.

[165] Batterink, L., Neville, H.J., 2013. The human brain processes syntax in the absence of conscious awareness. Journal of Neuroscience, 33(19), 8528-8533.

[166] Pulvermüller, F., Shtyrov, Y., Hasting, A.S., et al., 2008. Syntax as a reflex: Neurophysiological evidence for early automaticity of grammatical processing. Brain and Language, 104(3), 244253.

[167] Pulvermüller, F., Assadollahi, R., 2007. Grammar or serial order? Discrete combinatorial brain mechanisms reflected by the syntactic mismatch negativity. Journal of Cognitive Neuroscience, 19(6), 971-980.

[168] Sauerland, U., Gärtner, H.M. (Eds.) 2007. Interfaces + recursion = language? Berlin: Mouton de Gruyter.

[169] Terrace., 1983

[170] Rowe, D.L., Cooper, N.J., Liddell, B.J., et al., 2007. Brain Structure and Function Correlates of general and social cognition. Journal of Integrative Neuroscience, 06(01), 35-74.

[171] Atkinson, A.P., Wheeler, M., 2004. The grain of domains: The evolutionary-psychological case against domain-general cognition. Mind \& Language, 19(2), 147-176.

[172] Deaner, R.O., van Schaik, C.P., Johnson, V., 2006. Do some taxa have better domaingeneral cognition than others? A meta-analysis of Nonhuman primate studies. Evolutionary Psychology, 4(1), 149-196.

[173] Geary, D.C., 2004. Origin of mind: Evolution of brain, cognition, and general intelligence. Washington, DC, USA: American Psychological 
Association (APA).

[174] Roberts, M.J. (Ed.) 2007. Integrating the mind: Domain general versus domain specific processes in higher cognition. Hove, UK: Psychology Press.

[175] Martindale, C., Covello, E., West, A., 1986. Primary process cognition and hemispheric asymmetry. The Journal of Genetic Psychology, 147(1), 79-87.

[176] Pulvermüller, F., Kherif, F., Hauk, O., et al., 2009. Distributed cell assemblies for general lexical and category-specific semantic processing as revealed by $\mathrm{fMRI}$ cluster analysis. Human Brain Mapping, 30(12), 3837-3850.

[177] Loring, D.W., Meador, K.J., Lee, G.P., et al., 1992. Amobarbital effects and lateralized brain function: The Wada test. New York: SpringerVerlag.

[178] Abou-Khalil, B., 2007. An update on determination of language dominance in screening for epilepsy surgery: The Wada test and newer noninvasive alternatives. Epilepsia, 48(3), 442-455.

[179] Doss, R.C., Zhang, W., Risse, G.L., et al., 2009. Lateralizing language with magnetic source imaging: Validation based on the Wada test. Epilepsia, 50(10), 2242-2248.

[180] Gutbrod, K., Spring, D., Degonda, N., et al., 2012. Determination of language dominance: Wada test and fMRI compared using a novel sentence task. Journal of Neuroimaging, 22(3), 1-9.

[181] Gazzaniga, M.S., 1980. The role of language for conscious experience: Observations from splitbrain man. Progress in Brain Research, 54, 689696.

[182] Levy, J., Trevarthen, C., 1977. Perceptual, semantic and phonetic aspects of elementary language processes in split-brain patients. Brain, 100(1), 105-118.

[183] Goodman, R.A., Whitaker, H.A., 1985. Hemispherectomy: A review (1928-1981) with special reference to the linguistic abilities and disabilities if the residual right hemisphere. In Best, C.T. (Ed.), Hemispheric function and collaboration in the child. New York: Academic Press, pp. 121-156.

[184] Grabowecky, M., Kingstone, A., 2004. Can semantic information be transferred between hemispheres in the split-brain? Brain and Cognition, 55(2), 310-313.

[185] Lambert, A.J., 1991. Interhemispheric interaction in the split-brain. Neuropsychologia, 29(10), 941-948.

[186] Kingstone, A., Gazzaniga, M.S., 1995. Subcortical transfer of higher order information: More illusory than real? Neuropsychology, 9(3), 321-328.

[187] Lambert, A.J., Beard, C.T., Thompson, R.J., 1988. Selective attention, visual laterality, awareness, and perceiving the meaning of parafoveally presented words. The Quarterly Journal of Experimental Psychology, 40(4), 615-652.

[188] Linebarger, M.C., Schwartz, M.F., Saffran, E.M., 1983. Sensitivity to grammatical structure in socalled agrammatic aphasics. Cognition, 13(3), 361-392.

[189] Zurif, E., Grodzinsky, Y., 1983. Sensitivity to grammatical structure in agrammatic aphasics: A reply to Linebarger, Schwartz and Saffran. Cognition, 15(1-3), pp. 207-213.

[190] Linebarger, M.C., Schwartz, M.F., Saffran, E.M., 1983. Syntactic processing in agrammatism: $A$ reply to Zurif and Grodzinsky. Cognition, 15(1-3), 215-225.

[191] Schwartz, M.F., Linebarger, M.C., Saffran, E.M., et al., 1987. Syntactic transparency and sentence interpretation in aphasia. Language and Cognitive Processes, 2(2), 85-113.

[192] Hinzen, W., 2006. Mind design and minimal syntax. Oxford: Oxford University Press.

[193] Hinzen, W., 2007. An essay on names and truth. Oxford: Oxford University Press.

[194] Hinzen, W., 2011. Language and thought. In: Boeckx, C. (Ed.), The Oxford handbook of linguistic minimalism. Oxford: Oxford University Press, Chapter 22.

[195] Hinzen, W., 2012. The emergence of complex language. In McFarland, D., Stenning, K., McGonigle-Chalmers, M. (Eds.), The complex mind an interdisciplinary approach. Basingstoke, Hampshire: Palgrave Macmillan, pp. 243-263.

[196] Hinzen, W., Sheehan, M., 2013. The philosophy of universal grammar. Oxford: Oxford University Press.

[197] Terrace, H.S., 2005. Metacognition and the evolution of language. In Terrace, H., Metcalfe, J. (Eds.), The Missing link in cognition: Origins of self-reflective consciousness. Oxford: Oxford University Press, pp. 84-115.

[198] Forrester, G.S., 2008. A multidimensional approach to investigations of behaviour: Revealing structure in animal communication signals. Animal Behaviour, 76(5), 1749-1760.

[199] Kauffman, S.A., 2000. Investigations. Oxford: Oxford University Press.

[200] Boeckx, C., 2009. The nature of merge: Consequences for language, mind and biology. In Piattelli-Palmarini, M., Uriagereka, J., Salaburu, 
P. (Eds.), Of minds and language: a dialogue with Noam Chomsky in the Basque country. Oxford: Oxford University Press, pp. 44-57.

[201] Boeckx, C., 2012. The emergence of language, from a biolinguistic point of view. In Tallerman, M., Gibson, K.R. (Eds.), The Oxford handbook of language evolution. Oxford: Oxford University Press, pp. 492-501.

[202] Chomsky, N., 1990. On formalization and formal linguistics. Natural Language \& Linguistic Theory, 8(1), 143-147.

[203] Jackendoff, R., 1993. Patterns in the mind:
Language and human nature. New York: Harvester Wheatsheaf.

[204] Jackendoff, R., 2002. Foundations of language: Brain, meaning, grammar, evolution. Oxford: Oxford University Press.

[205] Jackendoff, R., 2007. A parallel architecture perspective on language processing. Brain Research, 1146, 2-22.

[206] Pinker, S., 1989. Learnability and cognition: The acquisition of argument structure. Cambridge, MA: MIT Press. 